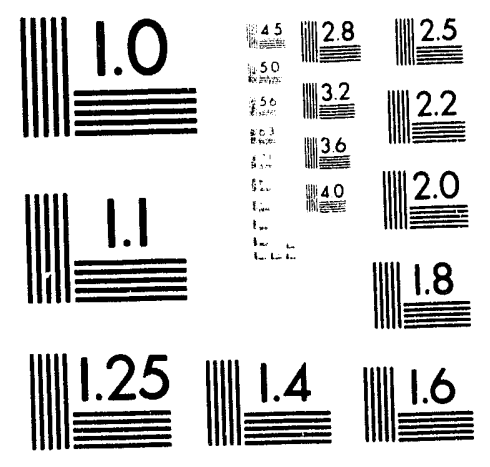



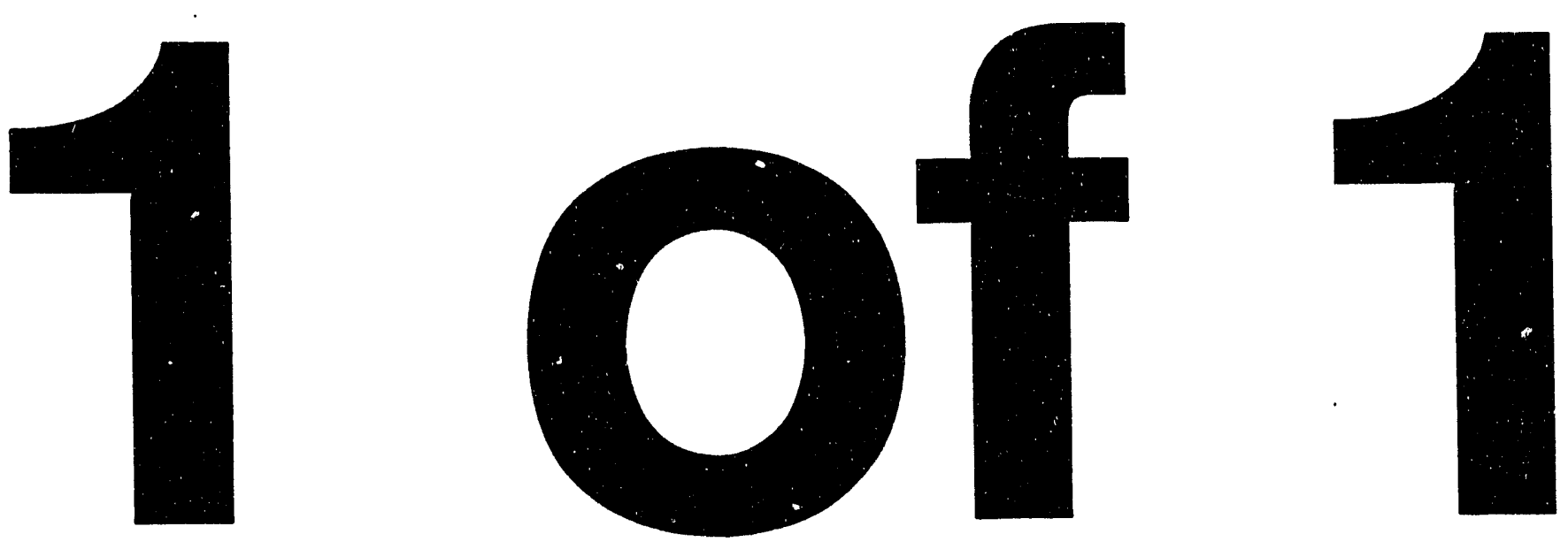


\section{STRATEGIES FOR FUNDAMENTAL AND EXPLORATORY \\ R\&D IN NATURAL GAS EXTRACTION}

$$
\text { ACO1-88FE } 61679
$$

\section{INTRODUCTION}

Natural gas is being increasingiy viewed as a key U.S. energy source. While gas supplies are sufficient today, there is concern as to whether sufficient supplies of affordably priced natural gas exist to support its expanded use as an environmentally clean substitute for oil, coal or other fuels.

One important strategy for expanding the volumes of affordable gas supplies is to undertake fundamental and exploratory research in gas development, production, and processing. The R\&D opportunities have been grouped according to the traditional phases of gas development and use, as follows :

- Extraction and Development Research: Efficient development of gas resources will require detailed reservoir diagnosis, more efficient well drilling and improved well stimulation. Advanced diagnostic tools, more powerful reservoir models, and improved development technologies would enable otherwise submarginal gas resources to become economically recoverable.

- Production and Processing Research: The primary opportunities in gas production and processing are in new technologies for the identification and separation of low quality gas and for the restimulation and production of abandoned gas fields.

The remainder of this strategy paper examines, in more detail, specific high priority R\&D topics for the DOE/FE AE\&PT program. 


\section{EXTRACTION AND DEVELOPMENT RESEARCH}

A most fruitful area for $R \& D$ in natural gas would be on techniques that would enable the industry to find and define the quality "sweet spots" of otherwise pervasive sub-marginal gas deposits. Such resource definition R\&D is particularly required for delineating the productive areas of low permeability deposits and for siting infill wells for reserve growth in discovered fields.

Improved drilling and reservoir stimulation, the artificial creation of flow paths deep in the earth, are the key technologies for producing low permeability and discontinuous gas reservoirs. As horizontal wells become more widely used, new techniques for logging and fracturing will be required. As stimulation methods are being applied to more complex reservoir mediums and settings, the simpler fracture models and stimulation fluids are proving to be inadequate. For efficient use of these technologies, a next generation of models, and fluids will be required, built on science.

\section{Identification of Permeability Featu}

Large volumes of natural gas have be n shcin to exist in unconventional gas reservoirs whose permeability is too low for economic production. For many such settings, even the use of induced fracturing, at large scale, is insufficient to achieve economic rates of gas flow. However, often nature has itself created flow paths through natural fractures that enable this resource to be efficiently produced. The early work on liniment studies in Devonian Shales was a first step in this area. However, the difficulty in interpreting the data as well as questions about the sub-surface extension of the surface liniments has limited the use of this exploration approach.

Recently, several investigators are pursuing the study of permeability features in two specific ways. First, work is underway to be able to distinguish between the deeply penetrating and the surface limited features, particularly to identify the major features that might be in contact with a gas bearing reservoir. Second, work is underway to identify or infer the existence 
of the smaller, more subtle natural fractures that would augment the major fracture systems-. Depositional studies, tectonic alteration assessments, and curvature analysis are methods being pursued.

A most productive area would be to combine these two paths of investigation and direct them, specifically, to the low permeability U.S. gas resource. A by-product of this work would be exploration technologies that could be applied to conventional oil, oil reserve growth and enhanced oil recovery.

\section{Modeling Reservoir Heterogeneities}

Reservoir heterogeneity and discontinuity are now recognized as major impediments to efficient gas recovery. Overcoming these impediments is the subject of work in geosciences research and "reserve growth." At present, considerable effort is being spent by the Bureau of Economic Geology, DOE, and GRI on the geologic and depositional aspects of reserve growth. However, little attention is being given to the essential reservoir simulation and modeling tools that will be required to either define the reservoir in ways usable in models or on the basic reservoir analysis tools themselves.

One new, promising technique (borrowed from Civil Engineering) is to adapt the Boundary Integral Equation Method (BIEM) to reservoir simulation of heterogeneity. The advantages of BIEM are two fold: (1) the boundary elements and data can be approximated by physical measurements or by the definition of the specific problem such as gas flow between genlogic facies separated by a lowpermeability shale; and (2) the BIEM reduces the domain of calculation by one dimension, thus reducing computer time and storage and enabling complex problems to be addressed on a microcomputer.

The development of reservoir engineering tools for analyzing reservoir continuity should be a valuable adjunct to the geologically oriented work currently being carried out. Moreover, the BIEM should have valuable application to the enhanced oil recovery and tar sand R\&D programs as well. 
Horizontal Drilling

Horizontal drilling can provide more efficiınt wellbore contact with a reservoir for a variety of settings, including fractured reservoirs, discontinuous reservoirs and those reservoirs wilh strong bottom water drives. In some instances, particularly in anisotropic reservoirs, horizontal drilling will also be preferable to using vertical wells with hydraulic fracturing.

Several associated technologies are required to expand the use and application of horizontal wells including: (1) a measurement while drilling system (MDW) for air drilled wells; (2) logging and other measurement systems for horizontal wells; and (3) stimulation techniques and models appropriate for horizontal wells.

\section{Improved Wellbore Materials}

As drilling proceeds to deeper and more corrosive settings, there is a need for lightweight, durable casing and tabulars that would maintain their integrity over a long time period. Even for shallow formations, there is need to look for plastics or fiberglass types of materials for well casing to reduce costs.

The key steps in this area are to establish the specific problems being encountered by the industry. Then, it would be valuable to integrate this improved materials work with the work being performed in the coal and synthetic fuels area of the program.

\section{Stimulation Fluid and Reservoir Rock Compatibility}

The producibility of natural gas from discontinuous or lower permeability conventional reservoirs and particularly from unconventional reservoirs (e.g. tight gas, Devonian shales, or coalbed methane) refuires long, conductive induced fractures. The role of the stimulation fluid is to wedge open and to distribute proppant along this fracture deep into the formation. An effective 
stimulation fluid needs to be compatible witl. the specific rock and reservoir properties, should cause minimal damage to matrix and fracture conductivity, and must rapidly "clean-up."

While new chemical mixtures are being devised that are favorable for creating the fracture and carrying proppant, only limited attention has been given to the interaction of these complex chemical mixtures with the host reservoir rock. Of particular interest would be three R\&D topics:

- the effects of capillary forces on fracturing fluid behavior, including the effects of contact angle, wettability, and surface and interfacial tension;

- the rheology of fracturing fluids, particularly the behavior of the fluid in response to shear rate, time and temperature and the ability to neutrailze ("break") the fluid once the job is complete; and

- the chemical interaction and compatibility of the fluid with the reservoir, particularly with clays, iron precipitate, and residual condensation.

The specific $R \& D$ to be conducted would involve detailed reservoir mineralogy and flow studies in conjunction with laboratory based chemical, fluid, and flow studies. Considerable synergy should be realized with any parallel capillary forces studies being conducted for the recovery of residual oil.

\section{Fracture Propagation and Stimulation Modeling}

Even though hydraulic fracturing is in wide use for gas recovery, the science and modeling of this technology remains only partly developed. For example, no 3-D model yet exists that can reliably predict the propagation and status of a hydraulic fracture. As the reservoir medium becomes more complex, such as in fractured reservoirs or coalbeds, the existing 2-D models falter as we11. 
Given the extremely complicated rock mechanics and physics of flow inherent in fracture propagation and stimulation modeling, analytical models or stand alone sub-models of the stimulation proven may be required. Then these analytical models and stand alone sub-models could be coupled for simulating the total process.

Since the Gas Research Institute has invested considerable research into the topic of stimulation modeling, this may be a productive area for joint DOE/GRI research.

\section{PRODUCTION AND PROCESSING RESEARCH}

The two major, overlooked opportunities in natural gas production and processing are the large subquality natural deposits and the innumerable abandoned (or near abandoned) gas fields and wells. These two research targets are novel in that they require the integration of resource definition, development strategy and production optimization. Improved understanding and characterization of these gas resources would be the first initial step, eventually conclud-ing with a field-based research experiment.

In addition, to provide cost efficient field level comparison, natural gas would be the preferred fuel. Thus, small package $\mathrm{NO}_{\mathrm{x}}$ removal technology would be most valuable for these types of application.

\section{Subquality Natural Gas}

Considerable volumes of "subquality ratural gas" -. natural gas that contains high concentrations of $\mathrm{CO}_{2}, \mathrm{~N}_{2}, \mathrm{H}_{2} \mathrm{~S}$ and inert gases - - are thought to exist in U.S. reservoirs. However, because such resources have traditionally been judged uneconomic, little effort has been spent on recording or classifying the nature and extent of this resource. With the advent of new membrane and gas separation technology (from other R\&D areas), it is timely to readdress this resource and to undertake the reservoir definition and research that is appropriate. 
The critical first step in this area would be a thorough resource assessment of subquality natural gas. Knowledge of this resource will help DOE shape the nature of its research on new and novel gas separation technologies appropriate to efficient removal of the by-product gases (which could be sold for other uses, such as for enhanced oil recovery) and cost-effective production of the separated natural gas.

The key initial $R \& D$ in this area would include:

- Preliminary assessment of subquality gas reserves and resources in place, to better define the size, composition and geographical distribution of this resource,

- Overview of subquality natural gas by-product markets, to establish the gas specifications and standards for by-product gas use,

- Preliminary assessment of gas processing technologies and costs, particularly on the new, emerging technologies, and

- Identification of selected technology areas that show promise for improved subquality gas separation and processing that can be readily applied in a field setting.

Important synergies should be realized with gas clean up and separation R\&D being conducted for shale oil processing and coal gasification.

\section{Abandoned or Near Abandoned Gas Reservoirs}

Considerable residual gas remains in abandoned reservoirs, where the reservoir pressures and the rates of gas flow are too low for continued economic production. However, it may be possible to "flood" tilis gas reservoir with another low cost gas and thus capture a portion of this abandoned resource. 
While the basic theory for such an approach is relatively straightforward, major Issues exist in the specific application of such an idea, including the mixing (or miscibility) of the injected gas and the in place natural gas, the breakthrough of the injected gas, and the specific field development practices to be used.

The critical first step would be to define the nature, extent, location, and condition of this abandoned gas resource. The resource definition work would be accompanied by laboratory work on mixing, fingering and separation of injected and reservoir gas. Reservoir engineering modeling of alternative gas flooding system would provide the analytic foundation for an eventual field experiment.

A second approach to the development of abandoned (or near abandoned) reservoirs, particularly where reservoir heterogeneity or low permeability are the constraining factors, would be the recompletion and stimulation of existing wells. The large number of such wells in the Appalachian Basin offers an attractive geological setting for such an initiative. Careful resource definition and modeling would be required before launching a field experiment.

Considerable synergy could be obtained by coordinating this work with the light oil enhanced oil recovery program.

\section{DISCLAIMER}

This report was prepared as an account of work sponsored by an agency of the United States Government. Neither the United States Government nor any agency thereof, nor any of their employees, makes any warranty, express or implied, or assumes any legal liability or responsibility for the accuracy, completeness, or usefulness of any information, apparatus, product, or process disclosed, or represents that its use would not infringe privately owned rights. Reference herein to any specific commercial product, process, or service by trade name, trademark, manufacturer, or otherwise does not necessarily constitute or imply its endorsement, recommendation, or favoring by the United States Government or any agency thereof. The views and opinions of authors expressed herein do not necessarily state or reflect those of the United States Government or any agency thereof. 

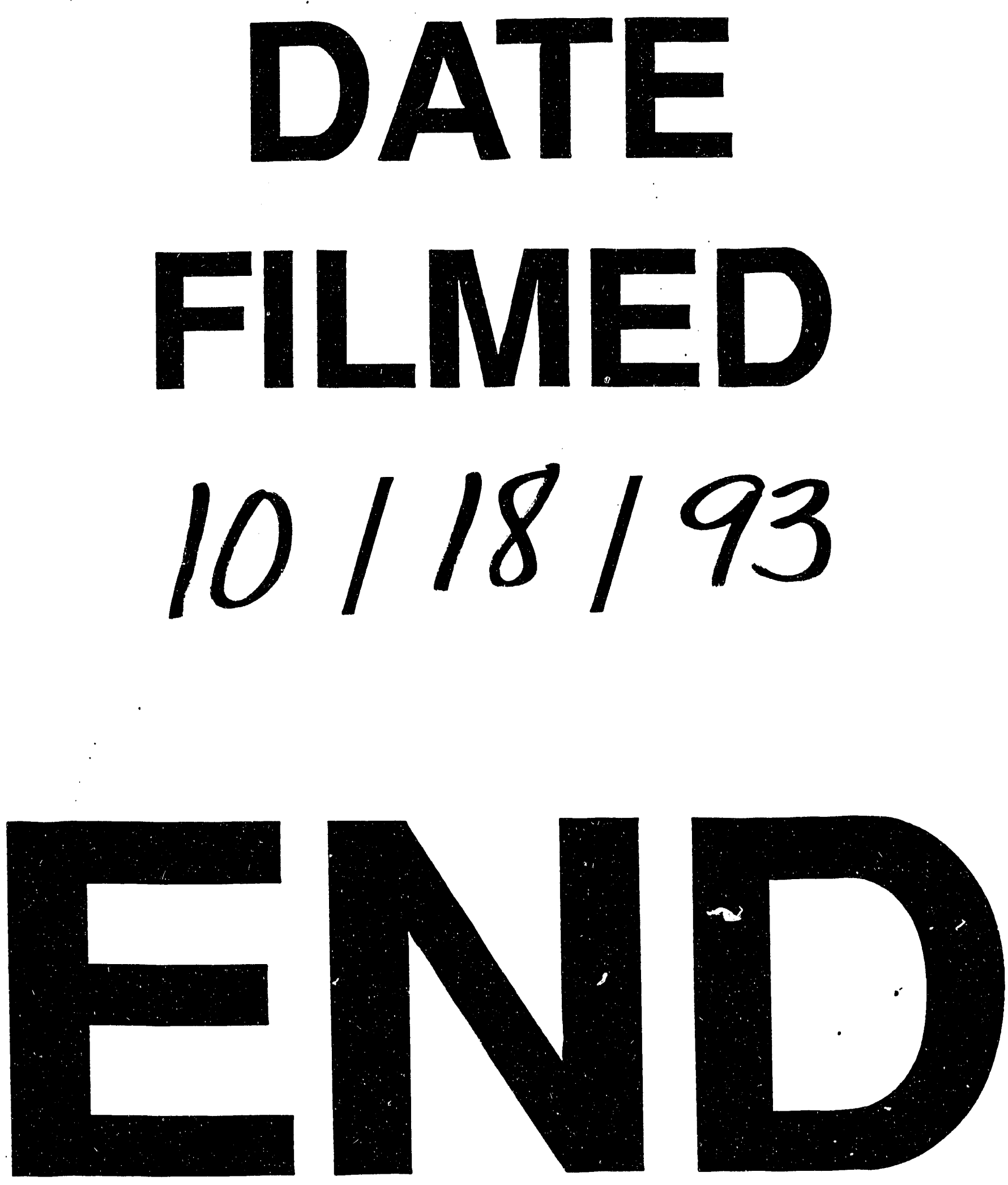


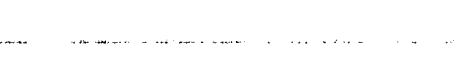

